\title{
Editorial da Edição Especial do Laboratório de Planejamento e Monitoramento Ambiental LPMA/UFSM e do Programa de Pós-Graduação em Tecnologia Mineral - UNIPAMPA
}

\author{
Pedro Daniel da Cunha Kemerich', Willian Fernando de Borba² \\ 'Professor Adjunto da Universidade Federal do Pampa, Caçapava do Sul, Brasil. \\ ${ }^{2}$ Acadêmico do Curso de Engenharia Ambiental e Sanitária da Universidade Federal de Santa Maria, Frederico Westphalen, Brasil
}

\section{INTRODUÇÃO}

Essa edição especial trás alguns dos trabalhos desenvolvidos pela equipe de trabalho do Laboratório de Monitoramento e Planejamento Ambiental - LPMA/UFSM, coordenada pelo Prof. Dr. Pedro Daniel da Cunha Kemerich, além de trabalhos desenvolvidos por Professores do Programa de PósGraduação em Tecnologia Mineral da UNIPAMPA, Campus Caçapava do Sul-RS nos últimos anos.

Nesta edição estão sendo apresentados trabalhos que envolvem os mais variados elos que englobam a questão ambiental, além de temas amplamente discutidos atualmente, tais como o aproveitamento de resíduos gerados em processos de tratamento de água; a situação dos resíduos sólidos no Brasil; propriedades físicas e contaminação de solos; vulnerabilidade ambiental e áreas de infiltrações máximas; indicadores de sustentabilidade; o papel do comitê de bacia hidrográfica na gestão dos recursos hídricos; os ruídos causados pela mineração de rochas e, ainda; um tema que está ganhando grande repercussão, porém, pouco conhecido: a questão ambiental envolvendo os cemitérios no Brasil.

Assim, a equipe agradece ao periódico a oportunidade disponibilizada, e desejamos a todos uma boa leitura.

Muito obrigado. 